\title{
TeleCommunity \\ Telecommunication for Persons with Mental Retardation - A Swedish Perspective
}

\author{
Jane Brodin \\ Department of Education, Stockholm University \\ S-106 91 Stockholm, Sweden.
}

\begin{abstract}
A study of the use of telecommunications for persons with moderate mental retardation has revealed that videotelephony may provide possibilities of participation in society and social life for persons with special needs. The Swedish ACE (Advanced Communications Experiments) is part of the European project TeleCommunity and based on data collected from a minitrial with two participants, and background information, questionnaires, interviews and observations with 24 adults with moderate mental retardation living in group homes. The results show that the effects of the impairments can be diminished, that communication and independence increase and that the quality of life may increase by using a videotelephone which is based on both visual and auditory impressions.
\end{abstract}

\section{Introduction}

The goal of the Swedish handicap policy is to avoid special solutions for people with disabilities as far as possible and instead make society as a whole accessible to all citizens. New technology offers many possibilities to facilitate daily life and to offer opportunities for development and independence provided that the technology is adapted to the persons with disabilities and made available. The goals are equality, participation, mutuality and communication, and the keywords are integration and normalization.

Most people consider it as natural to be able to participate in different activities in society and to use facilities offered. To have access to TV and to be able to use telecommunications are basic needs today. Most people regard it as impossible to live without having access to a telephone and today telefax machines are used not only at working sites, but also as a possible way to use telecommunications in private homes. In the near future, different telecommunication modes will be accessible to persons with disabilities, and telecommunication will be a natural part of daily life for all. Studies have revealed that still picture telephones and telefax machines can be used as support in communication for persons with different kinds of disabilities $[1,3,6,7,8]$. Persons who have never been able to communicate via an ordinary telephone have thus been able to send messages with different kinds of symbols to friends, parents and staff via the telenetwork.

Persons with mental retardation are individuals in need of special support for their daily living. In order to have access to ordinary services in the community and to be able to participate in social activities at 'normal' living conditions, people with mental retardation somtimes require more support than other groups of disabled persons due to 
intellectual, cognitive, motor and social factors, as well as the comprehension of additional disabilities. Mental retardation is an intellectual disability caused by a brain damage at an early developmental stage and it has no connection with mental illness. About $70 \%$ of this population also have multiple disabilities as motor disability, language and/or communication disorder, visual impairment and epilepsy, in addition to the mental retardation, which makes the situation extremely complex.

In Sweden the most commonly used graphic symbol system among persons with mental retardation is the Pictogram system. This symbol system is an augmentative and alternative way of communication and consists of about 650 symbols in white on a black background. The system is used mainly by persons with non-verbal communication and to support communication in persons with poorly developed spoken language.

However, techmical development seems to proceed more and more rapidly, not least within the telecommunication area. During the eighties a number of devices that facilitate communication have been introduced on the market e.g. automatic dialling and loudspeaking telephones. Three studies with still picture telephones for persons with moderate mental retardation, with profound mental retardation and with traumatic brain damages $[3,5]$ and one study with telex communication [2] were effected and make the basis for the Swedish minitrial and ACE (Advanced Communications Experiments) in the European project TeleCommunity. The results from these studies revealed that the frequency of use and the motivation and involvement increased, the ability to take initiatives increased, and the pictures transmitted became more relevant and functional over time. The still picture telephones also increased the possibilities to establish and develop social contacts.

Nine countries are involved in TeleCommunity, RACE 2033 (Research in Advanced Communications Technologies in Europe). The areas of disability covered in the study are visually impaired, deaf and hearing impaired, elderly and persons with mental retardation. Ireland, Norway, Portugal and Sweden have projects with participants with mental retardation.

A minitrial with two men with moderate mental retardation was carried through in 1993 [4]. The study focused on user aspects, technical aspects and staff aspects and formed the basis for the main study. The results showed that the quality of sound and image had to be improved, that the participants were positive and interested in using the equipment and that the staff found the task stimulating, but time-consuming, and stressed that the use of the videotelephones was a good support for communication for the participants. The empirical study with the 24 participants with moderate mental retardation (12 women and 12 men) started in March/April 1994 and the data collection will continue till December 31st, 1994.

\section{Aims of the Empirical Studies}

The overall aim of the studies carried through in the telecommunication area in Sweden has been to find out if children, adolescents and adults with different degrees of mental retardation may benefit from the use of still picture telephones, videotelephony and telefax communication in their daily lives. 
The concrete questions were:

Can transmission of pictures via the telecommunication network stimulate, facilitate and support communication?

Can communication with pictures on the telenet contribute to increased potential for social contacts?

Can picture telephones and telefax be considered as individual communcation aids for persons with mental retardation.

The overall aims of the Swedish ACE are:

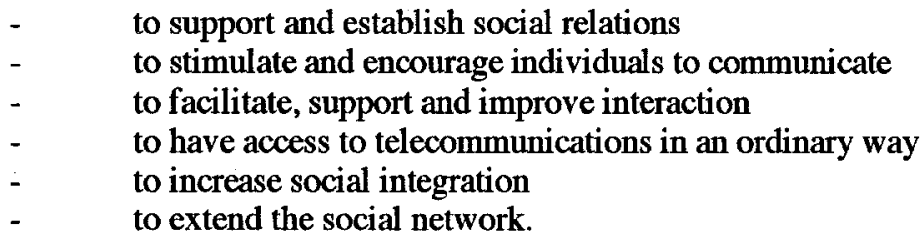

The main research interest is to study the communicative interaction and the social network for persons with moderate mental retardation. Another interest is to evaluate the user requirements and to investigate the need for support services for this population. The Swedish ACE has a socio-economic as well as an individual and society-oriented approach.

\section{Methods}

The methods used in TeleCommunity to perform the empirical study are background descriptions of the participants based on information from medical journals, questionnaires, semi-structured interviews with the participants, parents, staff from group homes and staff from day centers, telephone records completed by the staff, and assessment of the communicative ability of the the participants. Individual goal setting has been effected and the degree of goal attainment will be measured at several occasions and over time.

The study is based on a close co-operation between the participants with mental retardation, their parents and staff from group homes and day centers. Different sources and different contexts are used for the data collection.

\subsection{Equipment used}

The equipment used in the Swedish ACE is a videotelephony equipment, consisting of several different parts. The basis is an IBM compatible multimedia PC-terminal, an industrial type of CCD-camera and a document camera. The videotelephone software is designed for a Window environment. The public ISDN (integrated service digital 
network) is used for connections between the videotelephones. A microphone and a loudspeaker are included in the audio system. The outgoing audio and video signals are fed directly to the codec, which is a standard H.261 type codec from the Norwegian company Tandberg. The incoming audio signal is fed to the loudspeaker. The incoming and outgoing video signals are both visible on the PC-monitor. The user interface is a 20" colour screen and the modified concept keyboard has a built-in optimal sheet detecting facility. The screen shows the graphic Pictogram symbols received and transmitted during the call. The concept keyboard is used to start and finish calls as well as for the graphic symbol communication. The equipment also includes a camera with a built-in camera switch. A laser printer is included for printing the Pictogram symbols transferred during the call. For the awareness of incoming calls a paging system is used. Every user is equipped with an own tactile receiver.

\subsection{Subjects}

Six day centers, three in the Stockholm area and three in the Jönköping area are included in the study. Three of the day centers are thus situated in the south and three in the middle of Sweden within a distance of $500 \mathrm{~km}$. The participants are consequently divided into two separate groups. Twentyfour persons with moderate mental retardation are involved in the study. Twelve women and twelve men aged between 23 and 60 years participate. From each day center four persons with mental retardation are involved.

The staff involved in the project are occupational therapists, speech therapists and care nursers. The videotelephony training and calling are effected as part of their daily jobs which means that no extra staff have been engaged for the project. The staff (one main responsible and at least two or three other as co-trainers) have to fulfil certain criterias such as:

be interested in learning how the equipment works
be motivated and positive to teach and train the participants
be willing and able to spend time on training
be willing to document the work in writing
produce diary notes according to a special scedule.

The specific task they have to carry out are to be the "helping hand" of the participants with mental retardation. The maximum time for using the videotelephone for each individual has not been restricted, but each participant has to be involved in two telephone calls a week. In the introduction phase one day's staff education about communication in general and about telecommunication was conducted at each day center.

The participants have several disabilities in addition to the mental retardation. All of them have severe speech and communication disorders and are in great need of support for communication. The modes of communication are gestures, body language, sign communication, Pictogram symbols and a poorly developed spoken language. More than $50 \%$ of the participants have also visual impairments, hearing impairments and motor difficulties. Only eight of the participants had used a telephone before the project start. Today they live in group homes, this being a result of the abolishing of institutions for this population in Sweden. They have lived most of their lives in 
institutions and some of them have never been to school. All of the participants have a limited social network and many of them have no longer contact with their families.

\section{Results}

Although the TeleCommunity project will not be finished until December 1994, the presentation will give the very first results from the empirical study. Videosequences of the equipment and of the use of the videotelephones with some of the participants with moderate mental retardation will illustrate the promising results.

An early impression is that the participants are positive to the use of the videotelephones and that they are interested in getting in touch with other peers and in establishing new relations. This was also an experience from previous studies of the use of still picture telephones and telefaxes $[1,2,3]$. It is also remarkable to note that the participants have started to change their behaviour in some respects. Many of the participants are today, after some training, able to run the equipment by themselves and some of them also take initiatives to make calls and to chose communication partner. The reports from the staff illuminate that the use of the videotelephones has stimulated and supported the communicative ability and according to information from the parents the participants have extended their social network and made new friends of importance for them. The participants have for instance met at leisure time at special dances arranged for persons with mental retardation and they have recognized each other.

TeleCommunity seems to be a great challenge and opportunity for the participants and one assumption is that videotelephones may be a good communication aid for persons with special needs, and especially for persons with mental retardation..

\section{References:}

1. J. Brodin: Still Picture Telephones as Communication Aids for Persons with Mental Retardation. EuroRehab 3/1993, 163-168 (1993a)

2. J. Brodin: Telefax för personer med utvecklingsstörning [Telefax communication for persons with mental retardation]. Stockholm: Telia AB (The Swedish telecom) (1993b)

3. J. Brodin: Ny teknik för personer med i vuxen ålder förvärvade hjärnskador. [New technology for persons mental retardation. International Journal of with traumatic brain injuries] Stockholm University: Department of Education.(1994)

4. J. Brodin: Videotelephony for two persons with moderate mental retardation. International Journal of Rehabilitation Research, 17(3) (1994)

5. J. Brodin, E. Björck-Åkesson: Evaluation of still picture telephones for persons with mental retardation. Stockholm: Telia AB (The Swedish telecom) (1991) 
6. E. Hjelmqvist, E. Winroth Hallqvist:Slutrapport från Hemtelefax-projektet. Lässervice för synskadade personer. [Final report from the Hometelefax project. Reading service for visually impaired persons]. Göteborg University: Department of Psychology (1991)

7. S. von Tetzchner, F. Hesselberg, H.Langeland: Supervision of Habilitation via Videotelephone. In S. von Tetzchner Issues in Telecommunication and Disability, COST 219, Brussels (1991)

8. L.M. Pereira, M. Matos, J. Purificaçao, P.Lebre: Videotelephony and People with Mental Impairment.The Technical University of Lisbon, Tudor 1988(1992) 